\title{
Biofilm formation on pyrolytic carbon heart valves: Influence of surface free energy, roughness, and bacterial species
}

Pierre-Yves Litzler, MD, ${ }^{\mathrm{a}, \mathrm{b}, *}$ Laetitia Benard, ${ }^{\mathrm{b}, \mathrm{d}, *}$ Noëlle Barbier-Frebourg, MD, ${ }^{\mathrm{b}, \mathrm{c}}$ Sebastien Vilain, PhD, ${ }^{\mathrm{d}}$ Thierry Jouenne, $\mathrm{PhD}{ }^{\mathrm{c}, \mathrm{d}}$ Eric Beucher, ${ }^{\mathrm{e}}$ Claude Bunel, $\mathrm{PhD},{ }^{\mathrm{d}}$ Jean-François Lemeland, $\mathrm{MD},{ }^{\mathrm{b}, \mathrm{c}}$ and Jean-Paul Bessou, MD ${ }^{a}$

From the Department of Thoracic and Cardiovascular Surgery, ${ }^{\text {a }}$ Groupe de Recherche des Antimicrobiens et Micro-organismes, ${ }^{\mathrm{b}}$ and Institut Fédératif de Recherche Multidisciplinaire sur les Peptides, ${ }^{\mathrm{c}}$ Rouen University Hospital Charles Nicolle, Rouen, France; Unité Mixte de Recherche, Centre National de Recherche Scientifique, Rouen University, Faculty of Sciences, Mont Saint Aignan, France ${ }^{\mathrm{d}}$; and Centre Régional pour 1'Innovation et le Transfert de Technologies, Analyses et Surface, Louviers, France. ${ }^{\text {e }}$

Supported by a grant from: La Fondation de France, No. 99004608, and by A.R.C.T.C.V. (Research Association, Cardiac Surgery Department, Rouen University Hospital, Rouen, France).

Received for publication Dec 28, 2006; revisions received May 4, 2007; accepted for publication June 20, 2007.

Address for reprints: Pierre-Yves Litzler, MD, Department of Thoracic and Cardiovascular Surgery, Charles Nicolle University Hospital, 1, rue de Germont, 76000 Rouen, France (E-mail: pierre-yves.litzler@ chu-rouen.fr).

*PYL and LB contributed equally to this article.

J Thorac Cardiovasc Surg 2007;134:1025-32 $0022-5223 / \$ 32.00$

Copyright (C) 2007 by The American Association for Thoracic Surgery

doi:10.1016/j.jtcvs.2007.06.013
Objective: The aim of this study was to analyze the interaction of surface free energy and roughness characteristics of different pyrolytic carbon heart valves with three bacterial species on biofilm formation.

Methods: Three pyrolytic carbon heart valves (St Jude Medical [St Jude Medical Inc, Minneapolis, Minn], Sulzer Carbomedics [CarboMedics Inc, Austin, Tex], and MedicalCV [Medical Incorporated, Inver Grove Heights, Minn]) were tested. Roughness was measured by interferential microscopy and surface free energy by contact angle technique. To obtain a biofilm, prostheses were inserted into a bioreactor with Staphylococcus aureus P209, Staphylococcus epidermidis RP62A, or Pseudomonas aeruginosa PAO1. Adhesion was quantified by counting sessile bacteria. Morphologic characteristics of biofilms were evaluated with scanning electron microscopy.

Results: Roughness analysis revealed significant differences between the MedicalCV $(35.18 \pm 4.43 \mathrm{~nm})$ valve and St Jude Medical $(11.03 \pm 3.11 \mathrm{~nm} ; P<.0001)$ and Sulzer Carbomedics $(8.80 \pm 1.10 \mathrm{~nm} ; P<.0001)$ valves. Analysis of surface free energy revealed a higher level for the MedicalCV valve $\left(41.03 \mathrm{~mJ} \cdot \mathrm{m}^{-2}\right)$ than for both the Sulzer Carbomedics $\left(38.93 \mathrm{~mJ} \cdot \mathrm{m}^{-2}\right)$ and St Jude Medical $\left(31.51 \mathrm{~mJ} \cdot \mathrm{m}^{-2}\right)$ models. These results showed a correlation between surface free energy and bacterial adhesion for $S$ epidermidis and $P$ aeruginosa species. Regardless of the support, we observed significant adhesion differences for the three bacterial species. $S$ aureus was the most adherent species, $S$ epidermidis was the least, and $P$ aeruginosa was intermediate.

Conclusions: Our results suggest that adhesion of $S$ epidermidis and $P$ aeruginosa are dependent on pyrolytic carbon surface free energy and roughness, although $S$ aureus adhesion appears to be independent of these factors. Improvement of pyrolytic carbon physicochemical properties thus could lead to a reduction in valvular prosthetic infections.

$\mathrm{M}$ any prosthetic devices in cardiac and vascular surgery incorporate biomaterials such as pyrolytic carbon or polyester. Although satisfactory results have been obtained with these devices, the cumulative risk of endocarditis 5 years after prosthetic valve implantation ranges from $3.2 \%$ to $5.7 \%,{ }^{1}$ with a mortality between $30 \%$ and $80 \%{ }^{2}$ The management and treatment of these infections still remain controversial. ${ }^{3}$ In all cases, however, optimal treatment must be based on effective infection prevention. A better knowledge of the mechanisms involved in biomaterial infection is therefore essential.

The microorganisms that colonize prosthetic material usually form biofilms, which consist of an aqueous matrix of extracellular polymers where microbial cells 


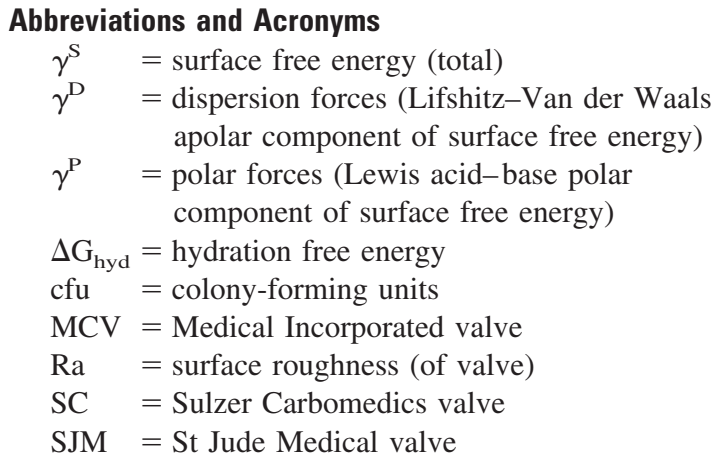

are embedded onto a surface. ${ }^{4}$ The characteristics of this particular growth pattern allow microorganisms to survive in hostile conditions. Indeed, organisms in biofilms are far more resistant (100 to 1000 times) to antimicrobial agents and host phagocytes than are their planktonic counterparts. ${ }^{5}$ Biofilm formation is known to be associated with intractable and persistent infections.

To assess the factors involved in biofilm formation, several authors have attempted to evaluate different hypotheses with various in vitro models and different types of materials. ${ }^{6,7}$ Although prosthetic graft infection is a major complication of cardiac surgery, biofilm formation on cardiovascular prostheses has been rarely studied. We therefore decided to develop an in vitro model with a new biofilm generator that was based on the specific biomaterials and bacteria most frequently involved in prosthetic infections. ${ }^{3}$ The aim of this study was to analyze the interaction of surface free energy and roughness of different pyrolytic carbon heart valves with three bacterial species in biofilm formation.

\section{Materials and Methods}

\section{Bacterial Strains and Inoculum Preparation}

Staphylococcus aureus P209 (6538P; American Type Culture Collection, Manassas, Va), Staphylococcus epidermidis RP62A (35984; American Type Culture Collection), and Pseudomonas aeruginosa PAO1 (15692; American Type Culture Collection) were used in the study. Bacteria were grown at $37^{\circ} \mathrm{C}$ in MuellerHinton broth (Difco Laboratories Inc, Detroit, Mich). After incubation for 18 hours, the cultures were centrifuged (1300g for 15 minutes), and the resulting pellet was washed and resuspended in sterile, distilled water. The population of the bacterial suspension was estimated by optical density measurements at $546 \mathrm{~nm}$ with reference to a calibration curve. To obtain a calibrated final concentration of $10^{6}$ colony-forming units $(\mathrm{cfu}) / \mathrm{mL}, 10^{9}$ bacteria were incubated for 48 hours at $37^{\circ} \mathrm{C}$ in a water bath in $1 \mathrm{~L}$ minimal salt medium of the following composition: $0.6-\mathrm{g} / \mathrm{L}$ tris(hydroxymethyl) aminomethane, $15-\mathrm{g} / \mathrm{L}$ tris(hydroxymethyl)aminomethane hydrochloride, $0.5-\mathrm{g} / \mathrm{L}$ ammonium chloride, $0.05-\mathrm{g} / \mathrm{L}$ calcium chloride, $0.05-\mathrm{g} / \mathrm{L}$ magnesium sulfate heptahydrate, $0.005-\mathrm{g} / \mathrm{L}$ ferrous sul- fate heptahydrate, $0.005-\mathrm{g} / \mathrm{L}$ magnesium sulfate hydrate, $2-\mathrm{g} / \mathrm{L}$ yeast extract, and $1-\mathrm{g} / \mathrm{L}$ glucose. The culture broth was changed after 24 hours of incubation.

\section{Cardiovascular Prostheses}

Three cardiovascular prostheses were tested. Two mechanical heart valves were made of pyrolytic carbon manufactured with silicon: St Jude Medical (SJM; St Jude Medical Inc, Minneapolis, Minn) and Sulzer Carbomedics (SC; CarboMedics Inc, Austin, Tex). One mechanical heart valve was made of pyrolytic carbon manufactured without silicon from MedicalCV (MCV; Medical Incorporated, Inver Grove Heights, Minn). The manufacturers generously provided these samples.

\section{Biofilm Reactor Model System Design}

Figure 1 shows the design of the model system developed for growing biofilms on cardiovascular prostheses. A 0.5 -inch silicone tube (Raumedic AG, Münchberg, Germany) was wired with connectors for extracorporeal circuits (Dideco SpA, Mirandola, Italy) to four chambers made of silicone rubber (Saint-Gobain Verneret, Charny, France) in parallel fashion. This device was sterilized, and sterile cardiovascular prostheses were placed in the silicone chambers before being connected to the bioreactor. The bioreactor contained $1 \mathrm{~L}$ minimal salt medium and was injected with a calibrated inoculum (approximately $10^{6} \mathrm{cfu} / \mathrm{mL}$ ). Batch bacterial culture was performed in a water bath at a constant temperature of $37^{\circ} \mathrm{C}$. The culture was recirculated at a flow rate of $192 \mathrm{~mL} / \mathrm{min}$ with a peristaltic pump (Stöckert Instrumente $\mathrm{GmbH}$, Munich, Germany). The medium was changed after 1 day of incubation. After 2 days, the flow was stopped, and the system was rinsed twice with $1 \mathrm{~L}$ 0.1-M phosphate buffer $(\mathrm{pH}$ 7) to remove weakly adherent bacteria. Prostheses were carefully sampled for scanning electron microscopy or bacterial quantitative analysis.

\section{Pyrolytic Carbon Surface Characteristic Measurements}

Surface roughness of the different pyrolytic carbon supports was measured by using differential interferometry (Micromap 512; Micromap Corporation, Tucson, Ariz). These measurements were carried out by an independent laboratory (CRITT Analyses et Surfaces, Louviers, France). The roughness $(R a)$ was characterized by its average amplitude, defined as follows:

$$
\mathrm{Ra}=\frac{1}{S} \iint_{S}|z| d S
$$

where $z$ is the height relative to a mean plane, and $S$ is the area of the measured zone.

\section{Surface Energy Determinations}

The surface free energies of the three valve models were determined by contact-angle goniometry, which measures the angle at which a liquid interface meets a solid surface. A computerized contact goniometer (NFT Communications Company, Tours, France) was interfaced with image-capture software (WINGOUTTE; NFT Communications) and analyzed with the software (WINCALC; NFT Communications).

Before use, supports were cleaned with ethanol and dried at $50^{\circ} \mathrm{C}$. For contact angle experiments, five calibrated droplets 


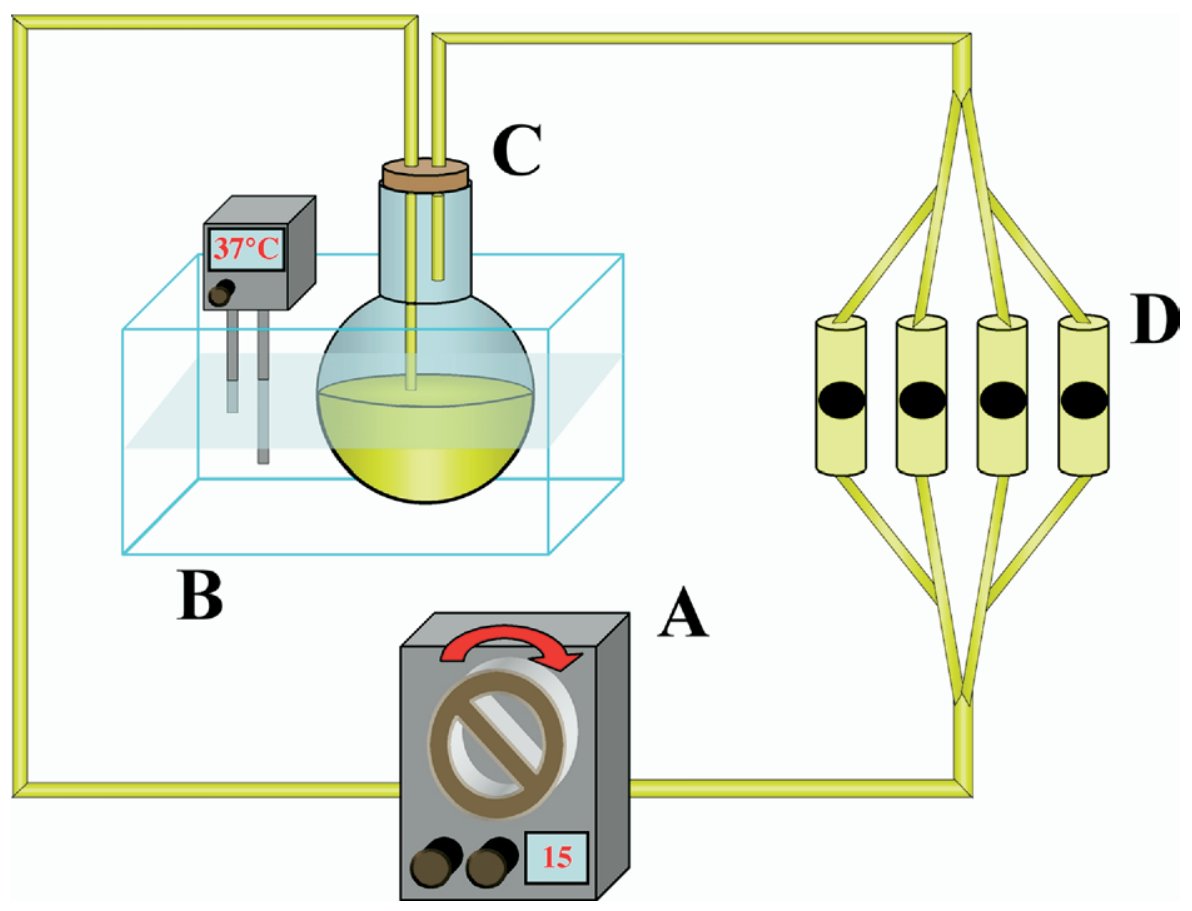

Figure 1. Model system developed for growing biofilms on pyrolytic carbon prostheses. $A$, Peristaltic pump; $B$, water bath at $37^{\circ} \mathrm{C} ; C$, batch bacterial culture; $D$, silicone chambers with cardiovascular prostheses.

(3 $\mu \mathrm{L}$ ) of ultrapure $(>99 \%)$ water, glycerol, and diiodomethane were deposited on the support. Contact angle measurements were immediately made by horizontal projection techniques. The mean values were obtained from three measurements of five calibrated droplets.

Surface free energy of the pyrolytic carbon support $\left(\gamma^{\mathrm{S}}\right)$ is the sum of components due to dispersion forces $\left(\gamma^{\mathrm{D}}\right.$, Lifshitz-Van der Waals apolar component) and polar forces $\left(\gamma^{\mathrm{P}}\right.$, Lewis acid-base polar component) obtained with the Van Oss model. ${ }^{8}$ The free interaction energy of surfaces with water, or hydration free energy $\left(\Delta \mathrm{G}_{\text {hyd }}\right)$ was calculated. According to Van Oss, ${ }^{8}$ the surface could be considered hydrophobic if $\left|\Delta \mathrm{G}_{\text {hyd }}\right|$ was greater than $113 \mathrm{~mJ} \cdot \mathrm{m}^{-2}$.

\section{Scanning Electron Microscopy}

After 48 hours of incubation, samples were rinsed twice with $1 \mathrm{~L}$ sterile phosphate buffer and removed for scanning electron microscopic fixation. Samples were fixed in a $2 \%$ glutaraldehyde, $0.1-\mathrm{mol} / \mathrm{L}$ cacodylate buffer $(\mathrm{pH} 7.4)$ for 30 minutes. They were then rinsed three times in cacodylate buffer $(0.2 \mathrm{~mol} / \mathrm{L}, \mathrm{pH} 7.4)$ for 10 minutes. Dehydration was performed with the following ethanol series of rinses: $30 \%, 50 \%$, and $80 \%$, each for 10 minutes, followed by $100 \%$ ethanol twice for 10 minutes each. Samples were dried in a heat chamber at $37^{\circ} \mathrm{C}$ for 24 hours before scanning electron microscopy (Cambridge Instruments Ltd, Ely, UK).

\section{Quantitative Analysis of Biofilm}

After 48 hours of incubation, valves were aseptically removed and washed twice in $0.1-\mathrm{mol} / \mathrm{L}$ potassium phosphate buffer $(\mathrm{pH} 7)$ to release weakly attached cells. They were then placed in sterile flasks containing $5 \mathrm{~mL}$ potassium phosphate buffer. Biofilm organisms were released from their substratum by successive steps of agitation on a vortex mixer and sonication (4 minutes at $50 \mathrm{~W}$, Deltasonic, Meaux, France) for 10 minutes. The resulting cell suspension was then serially diluted in decimal steps. Aliquots $(10 \mu \mathrm{L})$ of each dilution were spread on plate count agar (Difco Laboratories). The plates were incubated for 24 hours at $37^{\circ} \mathrm{C}$. Bacterial numbers were expressed as cfu per square centimeter of support.

\section{Statistical Analysis}

All experiments were performed at least in triplicate. Results were expressed as mean \pm SD. The data from these experiments were analyzed with nonparametric Mann-Whitney tests. Calculations were performed with Abacus Concepts StatView statistical software (SAS Institute, Inc, Cary, NC).

\section{Results}

\section{Surface Roughness Measurements}

All three pyrolytic carbon heart valves exhibited a low level of roughness $\left(\mathrm{Ra}_{\mathrm{SC}}=8.80 \pm 1.10 \mathrm{~nm}, \mathrm{Ra}_{\mathrm{SJM}}=11.03 \pm\right.$ $\left.3.11 \mathrm{~nm}, \mathrm{Ra}_{\mathrm{MCV}}=35.18 \pm 4.43 \mathrm{~nm}\right)$ relative to glass $(\mathrm{Ra}=$ $200 \mathrm{~nm})$, titanium $(\mathrm{Ra}=320 \mathrm{~nm})$, and polyvinylchloride $(\mathrm{Ra}=82 \mathrm{~nm})$. No significant difference was observed between SJM and SC valves $(P=.16)$. Significant differences were observed between SC and MCV valves $(P<$ $.0001)$ and between SJM and MCV valves $(P<.0001)$. For the three valve models tested, interferential microscopy revealed the presence of microcavities of approximately 1 to $2 \mu \mathrm{m}$ in width and $1 \mu \mathrm{m}$ in depth (Figure 2). 


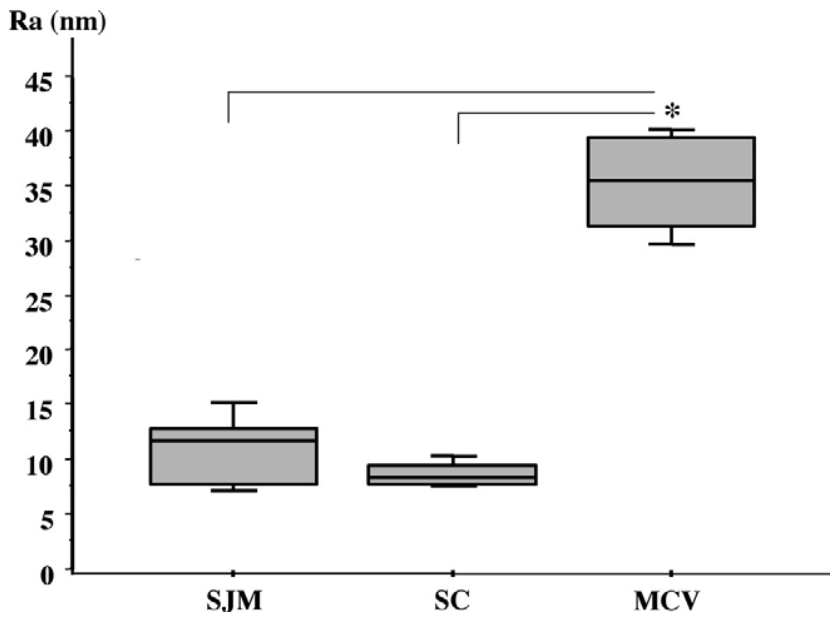

Figure 2. Roughness values (Ra) of three valve models tested. MedicalCV valve (MCV) shows higher roughness than St Jude Medical (SJM) and Sulzer Carbomedics (SC) valves. Asterisk indicates $\mathbf{P}<.0001$.

\section{Surface Energy Determinations}

Surface free energy $\left(\gamma^{\mathrm{S}}\right)$ measurements of the three pyrolytic carbon models revealed that the SJM model exhibited the lowest $\gamma^{\mathrm{S}}\left(31.51 \mathrm{~mJ} \cdot \mathrm{m}^{-2}\right)$, whereas the MCV model exhibited the highest $\gamma^{\mathrm{S}}\left(41.03 \mathrm{~mJ} \cdot \mathrm{m}^{-2}\right)$. The SC model exhibited an intermediate $\gamma^{\mathrm{S}}\left(38.93 \mathrm{~mJ} \cdot \mathrm{m}^{-2}\right.$; Table 1). We also observed the same distribution for the polar component $\left(\gamma^{\mathrm{P}}\right)$, but with a higher $\gamma^{\mathrm{P}}$ for the MCV valve (10.56 $\left.\mathrm{mJ} \cdot \mathrm{m}^{-2}\right)$ relative to both $\mathrm{SC}\left(2.87 \mathrm{~mJ} \cdot \mathrm{m}^{-2}\right)$ and SJM $\left(2.41 \mathrm{~mJ} \cdot \mathrm{m}^{-2}\right)$ models. Hydration free energy $\left(\Delta \mathrm{G}_{\mathrm{hyd}}\right)$ results, calculated according to the work of Van Oss, ${ }^{8}$ highlighted that SC and SJM are hydrophobic $\left(\Delta \mathrm{G}_{\text {hyd }}=\right.$ 120.22 and $116.17 \mathrm{~mJ} \cdot \mathrm{m}^{-2}$, respectively), whereas MCV is more hydrophilic $\left(\Delta \mathrm{G}_{\text {hyd }}=109.76 \mathrm{~mJ} \cdot \mathrm{m}^{-2}\right.$; Table 1$)$. The dispersive component (apolar, $\gamma^{\mathrm{D}}$ ) measurement revealed no major differences among the three valve models (Table 1). The adhesions of $S$ epidermidis and $P$ aeruginosa showed a correlation with $\gamma^{\mathrm{S}}$ (Figure 3) in accordance with the Baier curve. ${ }^{9}$

\section{Scanning Electron Microscopy}

Figures 4,5 , and 6 , respectively, illustrate 2-day-old biofilms of $S$ aureus, $S$ epidermidis, and $P$ aeruginosa devel-

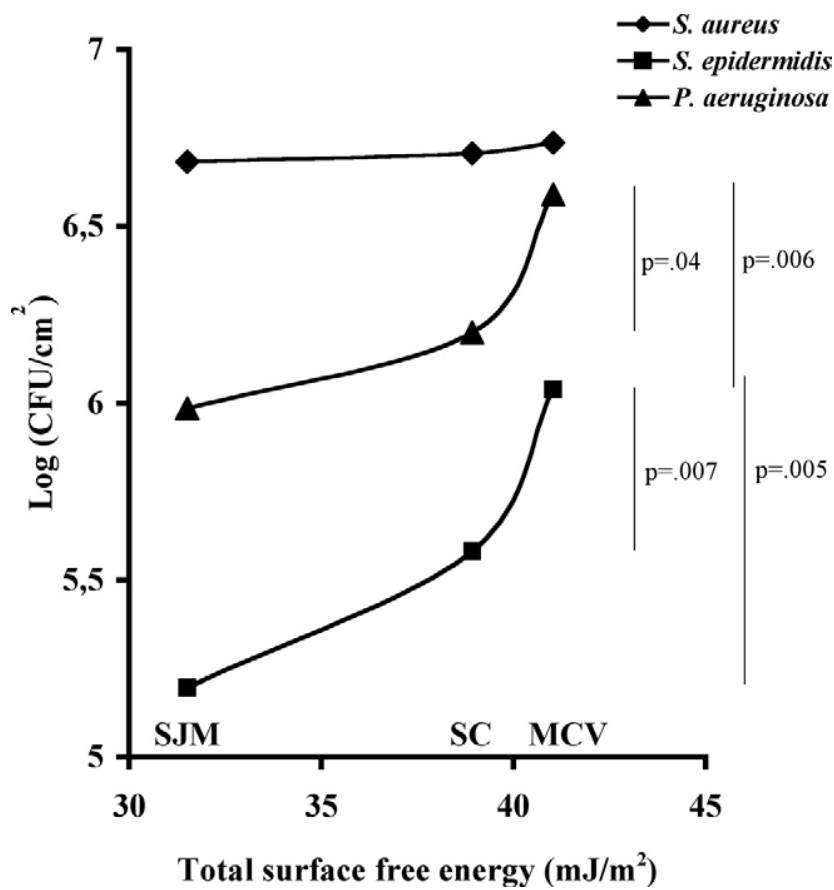

Figure 3. Bacterial adhesion according to pyrolytic carbon surface free energy. CFU, Colony-forming units; SJM, St Jude Medical; SC, Sulzer Carbomedics; MCV, MedicalCV.

oped on pyrolytic carbon. Regardless of the support used, biofilm coverage was patchy, although most areas had confluent growth and some areas were bare. Biofilm samples were similar within the four chambers both during the same chemostat run and between independent runs. Exopolysaccharide secretions were observed, revealing the anchorage of bacteria on pyrolytic carbon. We observed also an architectural discrepancy between the staphylococci and $P$ aeruginosa. The staphylococci exhibited a 3-dimensional biofilm structure, whereas cells of $P$ aeruginosa formed a monolayer embedded in an exopolysaccharide matrix. Microcavities did not appear to be the exclusive sites for bacterial adhesion. The microscopic observations revealed bacterial adherence outside microcavities; however, we could not assess the presence or absence of a microcavity under each microcolony.

TABLE 1. Surface free energy of the three pyrolytic carbon valve models

\begin{tabular}{|c|c|c|c|c|}
\hline Valve model & $\gamma^{\mathrm{P}}\left(\mathrm{mJ} \cdot \mathrm{m}^{-2}\right)$ & $\gamma^{D}\left(\mathrm{~mJ} \cdot \mathrm{m}^{-2}\right)$ & $\gamma^{\mathbf{S}}\left(\mathrm{mJ} \cdot \mathrm{m}^{-2}\right)$ & $\Delta G_{\text {hyd }}\left(\mathrm{mJ} \cdot \mathrm{m}^{-2}\right)$ \\
\hline Medical CV & 10.56 & 30.47 & 41.03 & 109.76 \\
\hline Sulzer Carbomedics & 2.87 & 36.06 & 38.93 & 120.22 \\
\hline Saint Jude Medical & 2.41 & 29.1 & 31.51 & 116.17 \\
\hline
\end{tabular}

$\gamma^{S}$, Total surface free energy; $\gamma^{P}$, polar component of surface free energy; $\gamma^{D}$, dispersion component of surface free energy; $\left|\Delta G_{h y d}\right|$, hydration free energy. 


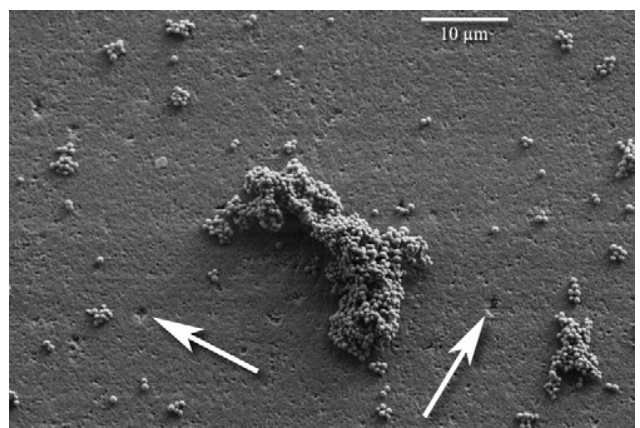

Figure 4. Example of 2-day-old biofilm of Staphylococcus aureus on Saint Jude Medical heart valve prosthesis (original magnification $\times 5000,3 \mathrm{kV})$. Note 3 -dimensional biofilm structure and microcavities on pyrolytic carbon (arrows).

\section{Quantitative Analysis of Biofilm}

Quantitative analysis on pyrolytic carbon revealed significant differences among the adhesions of the three bacterial species. $S$ epidermidis was the least adherent species (5.75 \pm $\left.0.53 \mathrm{cfu} / \mathrm{cm}^{2}\right), P$ aeruginosa was an intermediately adherent species $\left(6.24 \pm 0.44 \mathrm{cfu} / \mathrm{cm}^{2}\right)$, and $S$ aureus was the most adherent species $\left(6.71 \pm 0.43 \mathrm{cfu} / \mathrm{cm}^{2}\right)(P<.0001$ for $S$ aureus vs $S$ epidermidis, $P=.0019$ for $S$ aureus vs $P$ aeruginosa, $P=.0028$ for $S$ epidermidis vs $P$ aeruginosa; Table 2).

With regard to each valve model independently, we observed identical distributions of the three bacterial species. For all three models, $S$ epidermidis adhesion was significantly lower than both $S$ aureus adhesion $\left(P_{\mathrm{SJM}}=\right.$ $\left..0038, P_{\mathrm{SC}}=.0118, P_{\mathrm{MCV}}=.0005\right)$ and $P$ aeruginosa adhesion $\left(P_{\mathrm{SJM}}=.0231, P_{\mathrm{MCV}}=.0078, P_{\mathrm{SC}}=.0299\right)$. In the three valve models, we observed the lowest adhesion with $P$ aeruginosa relative to $S$ aureus; however, this difference was only significant in the SJM model $\left(P_{\mathrm{SJM}}=\right.$ $.0016, P_{\mathrm{MCV}}=.1209, P_{\mathrm{SC}}=.2922$; Figure 7 , Table 2).

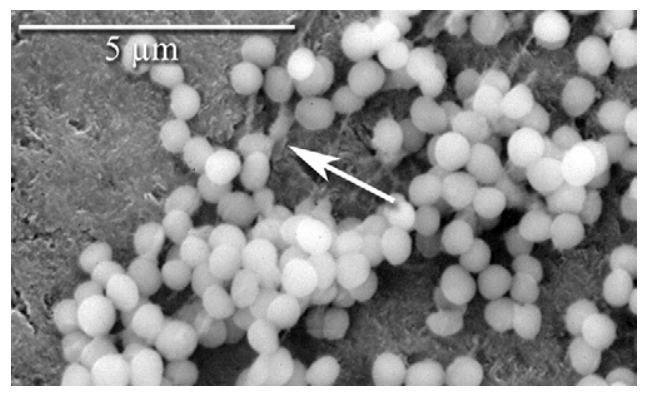

Figure 5. Example of 2-day-old biofilm of Staphylococcus epidermidis on Sulzer Carbomedics heart valve prosthesis (original magnification $\times 10,000,10 \mathrm{kV})$. Note exopolysaccharide secretion (arrow).

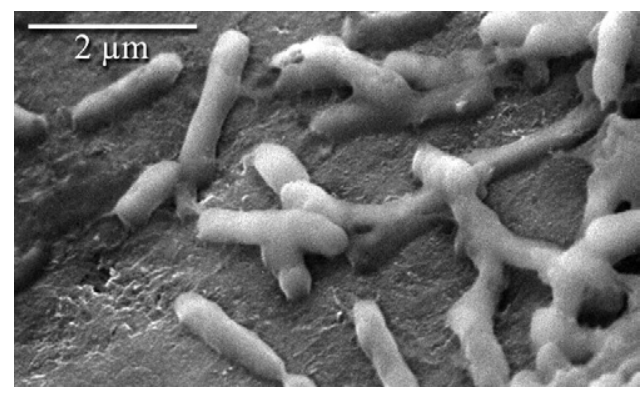

Figure 6. Example of 2-day-old biofilm of Pseudomonas aeruginosa on Medical CV heart valve prosthesis (original magnification $\times 15,100,10 \mathrm{kV})$.

The adhesions of the three species on the three valve models were also calculated with regard to the type of support. For each bacterial species, we observed an identical distribution for the three valve models: SJM was the least colonized valve, whereas MCV was the most colonized; however, these differences were only significant for $S$ epidermidis and $P$ aeruginosa between MCV and SJM or SC. There were no significant differences among the supports for $S$ aureus adhesion (Figure 8, Table 2).

\section{Discussion}

Several in vitro biofilm models have been reported in the literature, ${ }^{6,7}$ but to our knowledge no specific model has been developed to assess bacterial adhesion on cardiovascular prostheses. Although animal models have been widely used, it is essential to compare different biomaterials or bacterial strains under identical experimental conditions, which is often difficult in vivo. The blood flowing through an opened mechanical valve is essentially laminar. But the movement of the valve induces turbulent flow, which is not strictly identical between bileaflet or monodisk. This turbulent flow could influence the bacterial adhesion on these two types of valve. This potential confounding factor has no meaning in our assessment of the physical properties of pyrolytic carbon. Our model therefore assumes a continuous laminar flow through nonmobile leaflets.

TABLE 2. Numbers of the three strains according to the three valve models

\begin{tabular}{llcc}
\hline Valve model & $\begin{array}{c}\boldsymbol{S} \text { aureus } \\
\left(\mathbf{c f u} / \mathbf{c m}^{2}\right)\end{array}$ & $\begin{array}{c}\boldsymbol{S} \text { epidermidis } \\
\left(\mathbf{c f u} / \mathbf{c m}^{2}\right)\end{array}$ & $\begin{array}{c}\boldsymbol{P} \text { aeruginosa } \\
\left(\mathbf{c f u} / \mathbf{c m}^{2}\right)\end{array}$ \\
\hline MedicalCV & $6.74 \pm 0.25$ & $6.04 \pm 0.20$ & $6.59 \pm 0.30$ \\
Sulzer Carbomedics & $6.71 \pm 0.7$ & $5.58 \pm 0.30$ & $6.20 \pm 0.41$ \\
St Jude Medical & $6.68 \pm 0.24$ & $5.19 \pm 0.57$ & $5.99 \pm 0.41$ \\
Total & $6.71 \pm 0.43$ & $5.66 \pm 0.5$ & $6.25 \pm 0.44$ \\
\hline
\end{tabular}

Data are mean \pm SD. 


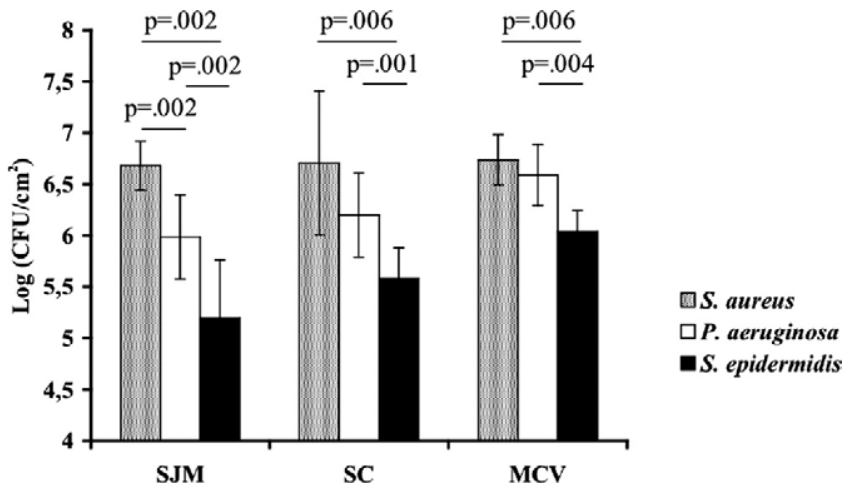

Figure 7. Enumeration of adherent bacteria on pyrolytic carbon according to valve model. CFU, Colony-forming units; SJM, St Jude Medical; SC, Sulzer Carbomedics; MCV, MedicaICV.

The choice of bacterial strains was related to their frequencies reported in the clinical literature. $S$ aureus and $S$ epidermidis are the most frequently implicated strains in native or prosthetic endocarditis and therefore were of major interest. ${ }^{3} P$ aeruginosa is frequently implicated in prosthetic vascular graft infections, ${ }^{10}$ although rarely observed in endocarditis. Moreover, $P$ aeruginosa, which is gram negative, is basically different from the gram-positive Staphylococcus species.

The mechanisms involved in microbial adhesion are complex and have not been fully assessed to date. Hydrophobicity, roughness, surface chemistry, and surface free energy all appear to play roles in the adhesion process. Nonspecific interactions such as electrostatic forces are also implicated in bacterial adhesion. ${ }^{11}$ For nonconductive implant materials as pyrolytic carbon, however, electrostatic interactions are usually negligible under physiologic conditions. $^{12}$

In our study, the three valve models can be divided into two groups. The first group, the SJM and SC valves, represents a flat leaflet of pyrolytic carbon manufactured with silicon exhibiting low roughness and surface free energy. The second group, the pyrolytic carbon MCV valve, represents a silicon-free curved disk, with significantly higher roughness and surface free energy. Interestingly, this model exhibited the greatest ability to be colonized. According to several authors, initial bacterial attachment is directly dependent on the surface roughness of the substratum. ${ }^{13,14}$ Pyrolytic carbon analysis revealed a low level of roughness. This physical parameter is dependant on the polishing performed during the heart valve manufacturing, specific to each manufacturer, which could also influence the physicochemical properties of the pyrolytic carbon. Nevertheless, scanning electron microscopy and differential interferometry revealed the presence of numerous microcavities. The exact role of microcavities in bacterial adhesion is difficult to establish. For technical reasons, we cannot assess presence or absence of microcavities under each microcolony. The increase in roughness could have a nonskid effect on bacterial cells during the initial phase of accretion. Moreover, as reported by Apilanez and colleagues, ${ }^{15}$ support roughness could be implicated not only in bacterial adherence but also in biofilm growth. In our study, however, roughness variation was weak (a few nanometers) among the three valve models, although differences were significant between the MCV valve and the SJM and SC valves.

Some other authors have seen no correlation between bacterial adhesion and roughness ${ }^{9,16}$ but do report a strong correlation with the surface free energy of the material tested. ${ }^{9}$ This phenomenon has been previously reported for erythrocytes by Clint and associates, ${ }^{17}$ who reported a higher level of erythrocyte adhesion on plastic with high surface free energy. In our study we observed three different surface free energy levels for the three pyrolytic carbons tested. For $P$ aeruginosa, Pereni and associates ${ }^{9}$ obtained the same variation of bacterial adhesion with different materials (stainless steel, polytetrafluoroethylene) exhibiting close values of surface free energy to those for our prosthetic heart valves. With $S$ epidermidis, we obtained the same correlation between bacterial adhesion and surface free energy as with $P$ aeruginosa. These results are also in accordance with the Baier curve. ${ }^{18}$ Indeed, the Baier curve demonstrates that whatever the materials tested, the lowest bacterial adhesion is obtained with a surface free energy level around $25 \mathrm{~mJ} \cdot \mathrm{m}^{-2}$. The SJM valve, with the lowest surface free energy level $\left(31.51 \mathrm{~mJ} \cdot \mathrm{m}^{-2}\right)$ and the lowest level of bacterial adhesion, is not very close to this "ideal value." A pyrolytic carbon with such a level would probably minimize bacterial adhesion and thus diminish the risk of prosthetic endocarditis.

Surprisingly, no correlation between adhesion of $S$ aureus and surface free energy was observed. Although $S$

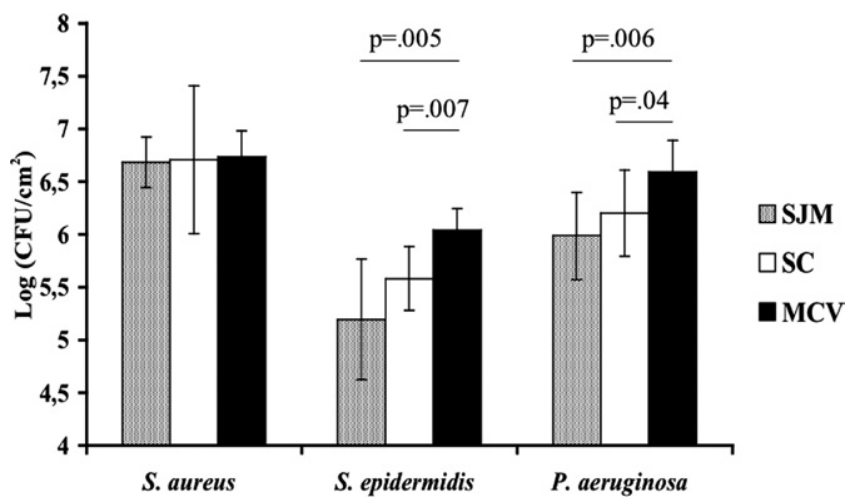

Figure 8. Enumeration of adherent bacteria on three valve models according to strain. CFU, Colony-forming units; SJM, St Jude Medical; SC, Sulzer Carbomedics; MCV, MedicaICV. 
aureus and $S$ epidermidis exhibited similar morphologic characteristics, their surface properties are known to be different. ${ }^{19}$ For example, $S$ epidermidis is relatively hydrophobic, whereas $S$ aureus is hydrophilic. ${ }^{16}$ Adhesion of $S$ aureus seems predominantly mediated by clumping factor A, a surface protein that promotes attachment to fibronectin, ${ }^{20}$ whereas adhesion of $S$ epidermidis is mediated principally by polysaccharide intercellular adhesion and polysaccharide adhesion. ${ }^{21}$ These adhesive proteins are known to bind plasma proteins that are absent in our circuit. This highlights the probable existence of unknown adhesive proteins, not linked to plasma protein, that could play a role in biofilm formation on biomaterials. Therefore, as observed in an ex vivo environment, a relevant portion of the biofilm formation in the host body could be independent of blood components. Further investigations are warranted to characterize any such proteins. Moreover, our model must be considered as an initial step. A necessary second step will be to study the influences of different blood proteins on bacterial adhesion. The addition of different blood proteins to our bioreactor would allow us to analyze the influences and the interactions of these proteins on bacterial adhesion. Another finding of this study was that $P$ aeruginosa, which is gram negative, was able to adhere to pyrolytic carbon valves under these identical experimental conditions. These observations are in contrast to reported findings suggesting that a blood-component conditioning film was essential for gram-negative bacteria to form a biofilm in an in vitro model $^{22}$ and that pyrolytic carbon prostheses do not allow adherence of microorganisms as long as they are free from thrombotic material. ${ }^{23}$ Moreover, contrary to Moreillon and colleagues $^{20}$ and François, Vaudaux, and Lew, ${ }^{24}$ who have demonstrated the importance of fibrinogen and clumping factor A in adhesion of $S$ aureus, the lack of plasma protein in our study did not prevent major biofilm formation.

In our in vitro model, we observed significantly higher adhesion of $S$ aureus than that of $S$ epidermidis on pyrolytic carbon, despite similar inoculum sizes. These results must be compared with those of clinical series. S aureus is known to be highly pathogenic and was identified as the main predictor of death (75\% vs $15 \%$ with other pathogens) in prosthetic valve endocarditis. ${ }^{25}$ The role of higher adhesive properties in infection persistence and pathogenicity is well known. ${ }^{21,26}$ In a series of patients with severe prosthetic endocarditis admitted to the intensive care unit, Wolff and associates $^{25}$ noted a predominance of $S$ aureus (33\% vs $12 \%)$ relative to $S$ epidermidis. This is in contrast with other reports, in which $S$ epidermidis has been the bacterial strain most frequently implicated in prosthetic valve endocarditis. ${ }^{3,23} S$ epidermidis is a saprophyte, whereas $S$ aureus is carried by only $20 \%$ of people. Nasal carriage of $S$ aureus is known to be a risk factor for postoperative wound infection after cardiac surgery. ${ }^{27}$ The lesser adhesive ability of $S$ epidermidis could be balanced with the ubiquity of this species to explain the occurrence of prosthetic infection with $S$ epidermidis. In contrast, the higher adhesive ability of $S$ aureus could explain its severity of infection. Surprisingly, $P$ aeruginos $a$ exhibited intermediate adhesion capacity for pyrolytic carbon in vitro, although this strain is rarely involved in endocarditis but frequently found in polyester vascular prosthetic infections, mostly from a wound contamination. $P$ aeruginosa is environmental and an opportunistic pathogen in human beings. Bacteremia with $P$ aeruginosa is thus quite unusual, and prosthetic heart valves are rarely exposed to these bacteria. This could explain the discrepancy with our in vitro model.

Prosthetic heart valves are made not only of pyrolytic carbon but also of polyester material in the sewing cuff. Bacteria have the ability to adhere to polyester as well as pyrolytic carbon. When endocarditis is present, it is always difficult to determine whether the primary adhesion appeared first on the polyester or on the pyrolytic carbon. The "Silzone experiment," however, which used a valve with a silver-impregnated polyester sewing ring (known for its bacteriostatic properties ${ }^{28}$ ), revealed a similar risk of endocarditis. ${ }^{29}$ The role of the polyester sewing ring in endocarditis formation therefore must be clarified.

In all cases, clinical studies reporting endocarditis data frequently combine late and early endocarditis, mechanical and bioprosthetic valves, ${ }^{3}$ mitral and aortic valves, ${ }^{30}$ or different bacterial species. It therefore seems difficult to elucidate the mechanisms implied in biofilm formation with such heterogeneous clinical data.

\section{Conclusions}

To improve endocarditis prevention, it seems essential to evaluate bacterial adhesion under controlled conditions. Clinical studies are unable to provide such reproducible conditions. In contrast, our in vitro model permitted us to study the influence of different parameters. The pyrolytic carbons studied showed differences in term of roughness and surface free energy, and our results suggest that the adhesions of $S$ epidermidis and $P$ aeruginosa are dependent on these physicochemical properties. In contrast, adhesion of $S$ aureus appears to be independent of these factors. With numerous studies independently examining the influences of different pyrolytic carbon properties, a more complete understanding of the mechanism of biofilm formation could be reached. This could be a first step in reducing the number of prosthetic device infections and further defining endocarditis formation profiles.

We thank Messrs Richard Medeiros, Vasilis Babaliaros, and Lowel Gerber for their advice in editing the manuscript, Mrs Irène Zimmerlin and Prof Jean-Paul Dupont for their technical assistance in scanning electronic microscopy, Messrs Jean-Michel Adde and Jerome Harmoy for their help in building the bioreactor, 
Prof Jean-Marc Saiter for welcoming us in his laboratory, Mrs Marie-France Hellot for the statistical analysis, and St Jude Medical, CarboMedics, and Medical Incorporated for generously providing the valve samples.

\section{References}

1. Arvay A, Lengyel M. Incidence and risk factors of prosthetic valve endocarditis. Eur J Cardiothorac Surg. 1988;2:336-9.

2. Vongpatanasin W, Hillis LD, Lange RA. Prosthetic heart valves. N Engl J Med. 1996;335:407-16.

3. Moreillon P, Que YA. Infective endocarditis. Lancet. 2004;363:13949.

4. Costerton JW, Lewandowski Z, Caldwell DE, Korber DR, LappinScott HM. Microbial biofilms. Anпи Rev Microbiol. 1995;49:711-45.

5. Ceri H, Olson ME, Stremick C, Read RR, Morck D, Buret A. The Calgary biofilm device: new technology for rapid determination of antibiotic susceptibilities of bacterial biofilms. J Clin Microbiol. 1999; 37:1771-6.

6. Kharazmi A, Giwercman B, Hoiby N. Robbins device in biofilm research. Methods Enzymol. 1999;310:207-15.

7. Bryers JD, Hendricks S. Bacterial infection of biomaterials. Experimental protocol for in vitro adhesion studies. Ann N Y Acad Sci. 1997;831:127-37.

8. Van Oss C. Forces interfaciales en milieu aqueux. Paris: Masson; 1996.

9. Pereni CI, Zhao Q, Liu Y, Abel E. Surface free energy effect on bacterial retention. Colloids Surf B Biointerfaces. 2006;48:143-7.

10. Kieffer E, Gomes D, Chiche L, Fleron MH, Koskas F, Bahnini A. Allograft replacement for infrarenal aortic graft infection: early and late results in 179 patients. J Vasc Surg. 2004;39:1009-17.

11. Bos R, van der Mei HC, Busscher HJ. Physico-chemistry of initial microbial adhesive interactions-its mechanisms and methods for study. FEMS Microbiology Reviews. 1999;23:179-230.

12. Wang J, Huang N, Yang P, Leng YX, Sun H, Liu ZY, et al. The effects of amorphous carbon films deposited on polyethylene terephthalate on bacterial adhesion. Biomaterials. 2004:25:3163-70.

13. Carlen A, Nikdel K, Wennerberg A, Holmberg K, Olsson J. Surface characteristics and in vitro biofilm formation on glass ionomer and composite resin. Biomaterials. 2001;22:481-7.

14. Kawai K, Urano M, Ebisu S. Effect of surface roughness of porcelain on adhesion of bacteria and their synthesizing glucans. J Prosthet Dent. 2000;83:664-7.

15. Apilanez I, Gutierrez A, Diaz M. Effect of surface materials on initial biofilm development. Biores Tech. 1998;66:225-30.

16. Lerebour G, Cupferman S, Bellon-Fontaine MN. Adhesion of Staphylococcus aureus and Staphylococcus epidermidis to the Episkin re- constructed epidermis model and to an inert 304 stainless steel substrate. J Appl Microbiol. 2004;97:7-16.

17. Clint JH. Adhesion and components of solid surface energies. Curr Opin Colloid Interface Sci. 2001;6:28-33.

18. Baier RE, Meyer AE, Natiella JR, Natiella RR, Carter JM. Surface properties determine bioadhesive outcomes: methods and results. J Biomed Mater Res. 1984;18:337-55.

19. Vaudaux PE, Huggler E, Lerch PG, Morgenthaler JJ, Nydegger UE, Schumacher-Perdreau $\mathrm{F}$, et al. Inhibition by immunoglobulins of Staphylococcus aureus adherence to fibronectin-coated foreign surfaces. J Invest Surg. 1989;2:397-408.

20. Moreillon P, Entenza JM, Francioli P, McDevitt D, Foster TJ, François $\mathrm{P}$, et al. Role of Staphylococcus aureus coagulase and clumping factor in pathogenesis of experimental endocarditis. Infect Immun. 1995;63: 4738-43.

21. Mack D, Becker P, Chatterjee I, Dobinsky S, Knobloch JK, Peters G, et al. Mechanisms of biofilm formation in Staphylococcus epidermidis and Staphylococcus aureus: functional molecules, regulatory circuits, and adaptive responses. Int J Med Microbiol. 2004;294:203-12.

22. Murga R, Miller JM, Donlan RM. Biofilm formation by gram-negative bacteria on central venous catheter connectors: effect of conditioning films in a laboratory model. J Clin Microbiol. 2001;39:2294-7.

23. Piper C, Korfer R, Horstkotte D. Prosthetic valve endocarditis. Heart. 2001;85:590-3

24. François P, Vaudaux P, Lew PD. Role of plasma and extracellular matrix proteins in the physiopathology of foreign body infections. Ann Vasc Surg. 1998;12:34-40.

25. Wolff M, Witchitz S, Chastang C, Regnier B, Vachon F. Prosthetic valve endocarditis in the ICU. Prognostic factors of overall survival in a series of 122 cases and consequences for treatment decision. Chest. 1995;108:688-94.

26. Costerton JW, Stewart PS, Greenberg EP. Bacterial biofilms: a common cause of persistent infections. Science. 1999;284:1318-22.

27. Kluytmans JA, Mouton JW, Ijzerman EP, Vandenbroucke-Grauls CM, Maat AW, Wagenvoort JH, et al. Nasal carriage of Staphylococcus aureus as a major risk factor for wound infections after cardiac surgery. J Infect Dis. 1995;171:216-9.

28. Tweden KS, Cameron JD, Razzouk AJ, Holmberg WR, Kelly SJ Biocompatibility of silver-modified polyester for antimicrobial protection of prosthetic valves. J Heart Valve Dis. 1997;6:553-61.

29. Grunkemeier GL, Jin R, Im K, Holubkov R, Kennard ED, Schaff HV Time-related risk of the St. Jude Silzone heart valve. Eur J Cardiothorac Surg. 2006;30:20-7.

30. Kassai B, Gueyffier F, Cucherat M, Boissel JP. Comparison of bioprosthesis and mechanical valves, a meta-analysis of randomised clinical trials. Cardiovasc Surg. 2000;8:477-83. 